\title{
A MATHEMATICAL MODEL OF SELECTING TRANSPORT FACILITIES FOR MULTIMODAL FREIGHT TRANSPORTATION
}

\author{
Olga Lingaitienè \\ Dept of Transport Technological Equipment, Vilnius Gediminas Technical University, \\ Jono Basanavičiaus g. 28 b, LT-03224 Vilnius, Lithuania \\ E-mail: o.lingaitiene@litrail.lt
}

Received 11 September 2007; accepted 20 November 2007

\begin{abstract}
A system of functional relationships between speed, traffic safety and costs, based on a set of criteria describing transportation quality is presented. The overall technological costs of transportation can be determined, when the costs of using road, rail and sea transport are calculated. For this purpose, a case study of creating a mathematical model for choosing the optimal route, taking into account time, costs and safety of transportation, is considered. The model evaluates the time of freight loading and storage at terminals. The total time of transportation, loading and storage differs for particular routes, depending on route structure and terminal operation. Freight safety is calculated in terms of insurance payments, depending on the type of goods, route and time of transportation. The model may be used for calculating any route, when applying the data on particular parks of vehicles.
\end{abstract}

Keywords: route, mathematical model, costs, time.

\section{Introduction}

Now, it is hardly possible to carry goods quickly, safely and at low cost to any place in the world by using only one transport facility. Therefore, all means of transport (i.e. road, railroad and water transport) should be integrated into a single system of transportation. For this purpose, rational functional relationships should be established between various means of transport, taking into account the volume and safety of goods as well as time and cost of transportation. The present paper aims to create and analyse a mathematical-economic model for choosing rational routes of freight transportation, using road (automobile), railway and water transport and taking into account the particular parks of various transport facilities.

\section{Functional relationships between the main parameters of transportation}

Transportation as a process can be described by a set of criteria, usually, speed, safety and costs of transportation are considered. Any of the above criteria describe quality of transportation from a particular perspective, therefore, all of them should be used for selecting a particular traffic route.

The generalized criterion describing the process of transportation embraces the total costs of carriage. The latter include technological costs of transportation, i.e. time expended, consisting of time of carriage, loading and storage as well as insurance costs:

$$
Z=\sum C+\sum T \cdot \tau+\sum D,
$$

where $Z$ means total costs of transportation, EUR; $C$ stands for technological costs of transportation, EUR; $T \cdot \tau$ means the total time expenses, EUR; $T$ is time of transportation, loading and storage, $h ; \tau$ stands for relative expenses in terms of time, EUR /h; $D$ means insurance expenses, EUR.

Technological transportation costs consist of costs of fuel (or other energy sources), oil or other maintenance materials, costs of maintenance and repairs, road (railroad or port) taxes, transport equipment insurance costs, drivers' payment and cargo forwarding expenses.

The costs of fuel (or other energy sources) are expressed in monetary units, while fuel costs are expressed in kilograms or litres, multiplied by the respective unit cost. The costs of fuel or energy are predicted, based on methods used for calculating expenses on particular means of transport. Fuel (or energy) costs are proportional to the run of a vehicle, therefore, they are expressed in EUR $/ \mathrm{km}$.

The costs of maintenance materials are also calculated, multiplying the expenses by the unit cost of the re- 
spective material. These costs are directly proportional to the total kilometres logged by a vehicle (or its service life). Therefore, they are usually expressed in EUR $/ \mathrm{km}$ as well.

Maintenance costs of a vehicle are expenses on maintaining it in good working order (e.g. by changing the worn-out parts, checking them up or taking some remedial measures). Repair costs are associated with restoring an operating state of a broken vehicle (e.g. after a road accident or failure) by a scheduled repair. Maintenance and repair costs are proportional to the kilometres logged by a vehicle, therefore, they are expressed in $\mathrm{EUR} / \mathrm{km}$.

Road taxes are calculated in different ways, depending on particular means of transport used, see TKTI Report (2005) and TKTI Report (2006). Automobile road tax makes a part of fuel costs. Port tax is calculated, depending on the length of the sea-front and the time of its use. Railroad tax is determined, taking into account overall costs of infrastructure (i.e. railroad maintenance costs, traffic regulation costs, as well as costs of additional services provided in handling freight or maintaining rolling stock). Usually, they are calculated by dividing overall annual railroad infrastructure costs by annual freight turnover expressed in ton $/ \mathrm{km}$. In this way, the cost of infrastructure for the following year is determined (and then corrected annually). The costs of railroad infrastructure are expressed in EUR/tkm or EUR $/ \mathrm{km}$.

The costs of transport equipment insurance are associated with the insurance of vehicles, mobile loading devices and containers. They are proportional to the amount of transport equipment insured. If the equipment is used without great delays, the costs become more heavily dependent on freight turnover or vehicle run, when the former is increasing. Therefore, in this case, the equipment insurance costs are expressed in EUR/ $\mathrm{km}$.

Expenses associated with drivers' payment depend on the work hours (also including payment to Sodra, income taxes and sick-leave payment). If the driver's work is well organized, the work hours are proportional to the kilometres logged by a vehicle. Therefore, the expenses on drivers' work payment are expressed in EUR/ $\mathrm{km}$.

Costs of freight forwarding depend on the conditions of the respective contracts (specifying the prices of services and their content). When the same services are provided for a long time, their costs are proportional to the distances covered. Therefore, these costs are also expressed in EUR/km.

General time expenditure embraces the time of transportation, loading and storage of goods, as well as the product of relative time expenses.

Relative time expenses are expressed in EUR/hour. This allows time expressed in hours to be converted into time expressed in EUR. When transportation time is expressed in EUR, it can be a dimension of a model, used alongside the expressions of other expenses.

Relative time expenses include payment for using transport facilities, possible fines for delayed cargo delivery, money lost because of the lack of free vehicles and mechanisms and service people to handle and deliver the cargo.
Total technological costs of transportation, EUR/ $\mathrm{tkm}$, can be calculated by the formula:

$$
\sum C=C_{a}+C_{g}+C_{j} \text {, }
$$

where $C_{a}$ denotes technological costs of carriage by road transport; $C_{g}$ denotes technological costs of carriage by rail transport; $C_{j}$ denotes technological costs of carriage by sea transport.

The total transportation loading and storage time has two components: transportation time and time of loading and storage at the terminal. It is calculated in the following way:

$$
T=\sum T_{t}+\sum T_{s},
$$

where $T_{t}$ is transportation time, $\mathrm{h} ; T_{s}$ is loading and storage time, $\mathrm{h}$.

The time of transportation is time required for carrying the cargo. Loading and storage time is time expended in warehouses on loading, unloading and storing the cargo. Overall time of transporting, loading and storage of goods differs, depending on the route and terminal operation.

Insurance costs $D$ are associated with insurance payment. Vehicle insurance costs are not included in these expenses (because they refer to technological expenses). Therefore, only cargo insurance costs, depending on the type of cargo, route and time of transportation are considered.

The total time can be expressed as:

$$
T=l_{a} / V_{a}+l_{g} / V_{g}+l_{j} / V_{j}+T_{s},
$$

where $l_{a}, l_{g}, l_{j}$ denote distance covered by a particular means of transport (cars, rail or sea transport), km; $V_{a}, V_{g}, V_{j}$ denote speed of the respective means of transport, $\mathrm{km} / \mathrm{h}$;

\section{The relationship describing transportation by road transport}

Technological costs of transportation are calculated by determining the tariff of carriage by car, EUR/tkm and using the formula:

$$
C_{a}=k_{a} \cdot m_{a} \cdot l_{a},
$$

where $l_{a}$ is the distance covered by road transport, $\mathrm{km} ; m_{a}$ is mass of goods carried by road transport, $\mathrm{t} ; k_{a}$ denotes costs of $1 \mathrm{tkm}$ carriage by road transport, EUR/tkm.

The product of cargo mass and distance is called transport work and is expressed in tkm. Multiplying it by the costs per tkm, technological costs of transportation by automobile transport are obtained. The costs of $1 \mathrm{tkm}$ carriage by road transport depend on the vehicle speed:

$$
k_{a}=k_{a v} \cdot k_{v 1},
$$

where $k_{a v}$ denotes the average costs of carriage by road transport, EUR/tkm; $k_{v 1}$ is coefficient evaluating the vehicle speed.

The coefficient, estimating automobile speed, can be calculated by the formula:

$$
k_{v 1}=a_{a}+b_{a} \cdot V_{a}+c_{a} \cdot V_{a}^{2},
$$


where $a_{a}, b_{a}$ and $c_{a}$ are the equation coefficients, estimating motor road resistance.

By substituting the values of the coefficients, see investigation of Lingaitienè (2006), we will get the equation:

$$
k_{v 1}=0.216+0.000952 \cdot V+0.0238 \cdot 10^{-3} \cdot V^{2} \text {. }
$$

By substituting the formula (8) for (6), we obtain:

$$
k_{a}=k_{a v} \cdot\left(0.216+0.000952 \cdot V+0.0238 \cdot 10^{-3} \cdot V^{2}\right)
$$

The average transportation costs of carriage by a vehicle make $0.02107 \mathrm{EUR} / \mathrm{tkm}$. This result is obtained by assuming that the vehicle capacity is 20 tons, diesel oil consumption for $100 \mathrm{~km}$ makes 28 litres and the cost of 1 litre of diesel oil is 0,87 EUR.

By substituting the formula (9) for (5), we obtain:

$$
\begin{aligned}
& C_{a}=0.02107 \cdot(0.216+0.000952 \cdot V+ \\
& \left.0.0238 \cdot 10^{-3} \cdot V^{2}\right) \cdot m_{a} \cdot l_{a} .
\end{aligned}
$$

\section{The relationship to determining costs of freight transportation by rail}

Technological costs of transportation by rail are found by determining the tariff, EUR/tkm, and using a formula:

$$
C_{g}=k_{g} \cdot m_{g} \cdot l_{g}
$$

where $l_{g}$ is the distance of transportation by rail transport, $\mathrm{km} ; m_{g}$ is mass of goods transported by rail transport, $\mathrm{t}$; $k_{g}$ is cost of $1 \mathrm{tkm}$ carriage by rail transport, EUR/tkm.

The costs of $1 \mathrm{tkm}$ carriage by rail transport depend on the speed of transport:

$$
k_{g}=k_{g v} \cdot k_{v 2} \text {, }
$$

where $k_{g v}$ denotes the costs of carriage by rail transport, EUR/tkm; $k_{v 2}$ is coefficient evaluating the speed of the train.

The average costs of carriage by rail transport depend on the distance to the place of destination. In the tariff table (see investigation of Lingaitiene 2006), a discrete relationship between the transportation tariffs and distance is given. Approximating these values by the mean square method, a power function is obtained. Based on the tariffs in 2006:

$$
k_{g v}=0.2047 \cdot l_{g}^{-0.1515} \text {. }
$$

The power less than one means that the longer the distance, the lower its effect on the function and the tariff of carriage. A minus means the inverse proportionality.

The coefficient, estimating the speed of a rail vehicle, can be calculated by the formula:

$$
k_{v 2}=a_{g}+b_{g} \cdot V_{g}+c_{g} \cdot V_{g}^{2},
$$

where $a_{g}, b_{g}$ and $c_{g}$ are the equation coefficients, estimating rolling resistance of the railroad.

By substituting coefficients, we will get:

$$
k_{v 2}=0.739+0.00325 \cdot V+0.0814 \cdot V^{2} \text {. }
$$

By substituting the equations (13) and (15) for (12), we will get:

$$
\begin{aligned}
& k_{g}=0.2047 \cdot l_{g}^{-0.1515} \cdot(0.739+0.00325 \cdot V+ \\
& \left.0.0814 \cdot V^{2}\right) .
\end{aligned}
$$

By substituting the formula (16) for (11) and making some operations, we obtain:

$$
\begin{aligned}
& C_{g}=0.2047 \cdot l_{g}^{0.8485} \cdot m_{g} \cdot(0.739+0.00325 \cdot V+ \\
& \left.0.0814 \cdot V^{2}\right) .
\end{aligned}
$$

\section{The relationship describing costs of freight transportation by sea}

Technological costs of transportation are obtained by determining the tariff, EUR/tkm, of carriage by sea transport, the respective insurance costs and by using the formula:

$$
C_{j}=k_{j} \cdot m_{j}
$$

where $m_{j}$ is mass of goods carried by sea transport, $\mathrm{t} ; k_{j}$ is mass of goods carried by sea transport, EUR/t.

The costs of carrying one tkm of goods by sea transport depend on the ship speed:

$$
k_{j}=k_{j v} \cdot k_{v 3}
$$

where $k_{j v}$ denotes average costs of sea transport, EUR/ $\mathrm{tkm} ; k_{v 3}$ is a coefficient to evaluate the ship speed.

Average costs of freight transportation by sea transport are calculated by approximating a discrete tariff and distance relationship by a least square method:

$$
k_{j v}=-6 \cdot 10^{-6} \cdot l_{j}^{2}+0.0677 \cdot l_{j} ;
$$

where $l_{j}$ is a distance covered by sea transport, $\mathrm{km}$.

The coefficient, estimating automobile speed, can be calculated by the formula:

$$
k_{v 3}=a_{j}+b_{j} \cdot V_{j}+c_{j} \cdot V_{j}^{2},
$$

where $a_{j}, b_{j}$ and $c_{j}$ are the equation coefficients, estimating ship resistance in motion.

By substituting value of coefficients for (21), we will get:

$$
k_{v 3}=0.8483+0.00373 \cdot V+0.09338 \cdot V^{2} .
$$

By substituting (20) and (22) for the equation (19), we will get:

$$
\begin{aligned}
& k_{j}=\left(-6 \cdot 10^{-6} \cdot l_{j}^{2}+0.0677 \cdot l_{j}\right) . \\
& \left(0.8483+0.00373 \cdot V+0.09338 \cdot V^{2}\right) .
\end{aligned}
$$

By substituting equation (23) for (18), we will get:

$$
\begin{aligned}
& C_{j}=\left(-6 \cdot 10^{-6} \cdot l_{j}^{2}+0.0677 \cdot l_{j}\right) . \\
& \left(0.8483+0.00373 \cdot V+0.09338 \cdot V^{2}\right) \cdot m_{j} .
\end{aligned}
$$

A negative sign (minus) before the square coefficient number means that the function extreme is a maximum. It is found when the distance of transportation is about $5000 \mathrm{~km}$. In carrying goods on the territory of the EU member-states at a distance up to $5000 \mathrm{~km}$, the 
maintenance, fuel and other expenses are calculated in European prices. When the distances are longer, maintenance and refuelling operations may be performed, for instance, in South American or African countries, where prices are lower. Therefore, the transportation tariffs are also decreased. Fuel and maintenance costs for a ship, covering a distance from 4 to 6 thous. $\mathrm{km}$, are decreased. However, in this case, it is not possible to use 3rd country's cheap resources. This is shown by the extreme on the respective graph.

\section{Calculating overall technological costs of transportation}

Let us substitute the equations (10), (17), (24) and (4) for the equation (1). Then, overall costs of carrying goods by different means of transport (e.g. automobiles, trains or ships) can be calculated in the following way:

$$
\begin{aligned}
& Z=0.02107 \cdot m_{a} \cdot l_{a} \cdot \\
& \left(0.216+0.000952 \cdot V_{a}+0.0238 \cdot 10^{-3} \cdot V_{a}^{2}\right)+ \\
& 0.2047 \cdot m_{g} \cdot l_{g}^{0,8485} \cdot \\
& \left(0.739+0.00325 \cdot V_{g}+0.0814 \cdot 10^{-3} \cdot V_{g}^{2}\right)+ \\
& m_{j} \cdot\left(-6 \cdot 10^{-6} \cdot l_{j}^{2}+0.0677 \cdot l_{j}\right) \cdot \\
& \left(0.8483+0.00373 \cdot V_{j}+0.09338 \cdot 10^{-3} \cdot V_{j}^{2}\right)+ \\
& \left(l_{a} / \Delta V_{a}\right) \cdot \tau_{a}+\left(l_{g} / \Delta V_{g}\right) \cdot \tau_{g}+ \\
& \left(l_{j} / \Delta V_{j}\right) \cdot \tau_{j}+T_{s} \tau_{s}+\sum D,
\end{aligned}
$$

where $V_{a}, V_{g}, V_{j}$ denote speed of a respective means of transport, $\mathrm{km} / \mathrm{h} ; \tau_{a}, \tau_{g}, \tau_{j}$ are relative costs in terms of time of transporting goods by a respective means of transport, EUR/h; $\Delta V_{a}, \Delta V_{g}, \Delta V_{j}$ mean the difference $V_{p l}-V_{f}=\Delta V_{i}$ between the planned and actual speed, $V_{p l}$ and $V_{f}$ respectively, when $i=a, g, j, \mathrm{~km} / \mathrm{h}$. They express nonprovisioned downtime (detention) on the route between terminals (caused by customs operations, road repair, accidents, etc.); $T_{s}$ is loading and storage time, $\mathrm{h}$, different for each terminal because it depends on terminal capacity (methods of loading, equipment) and control system, and is calculated individually; $\tau_{s}$ denotes relative costs in terms of time of freight storage at the terminal, taking into account costs of loading and unloading, $\mathrm{EUR} / \mathrm{h}$. This value may be determinated or variable, depending on the time of storage, type of goods and operations; $\sum D$ denotes insurance costs, EUR.

As shown in (25), a model of determining overall transportation costs should include the costs of cargo handling at the terminals and insurance costs. These types of expenses differ considerably, largely depending on particular loading operations and storage, as well as insurance and agreements made between the interested states.

\section{Determining the efficiency function}

The efficiency of freight transportation is determined by three main criteria: costs, time and reliability (safety). The suggested model does not specifically consider freight safety (from technical perspective) because it is hardly possible to assess it, based on the available statis- tical data. Besides, it differs from route to route. However, this aspect is reflected to some extent in the insurance costs. Therefore, only time and costs are considered. Since there are two factors, two priorities will be established.

\section{Alternative 1:}

Efficiency function $Z \geq \min$;

Limitation $\quad T<T$ max.

The efficiency function for the first alternative is to minimize costs, when time of transportation is limited. This variant is acceptable, when a customer wants to get a service at minimum cost, while the time of transportation is not pressing. This is the case, when freight is regularly delivered, goods are distributed on the way and time of carriage is not important. For example, while delivering fuel to a power station, it is important to provide a certain amount of fuel at regular intervals and at minimum costs. However, the time of fuel transportation and routes are not essential for the executives of the station.

\section{Alternative 2:}

\section{Efficiency function $T \geq \min$;}

Limitation $\quad Z<Z \max$.

The efficiency function for the second alternative is to minimize time, when transportation costs are limited. This variant is acceptable when a customer needs urgent freight delivery and is ready to pay not a small sum of money for it. For example, in delivering parts to assembly shops, they should be provided in time (because in modern assembly shops parts are not stored and should be delivered exactly before assembling). Therefore, time is the priority in parts delivery.

\section{A case study of the model application}

A schematic view of possible routes is given in Fig. 1.

Here, $A, B$ are the beginning and end of route; 1,2 , 3, 4 are points of cargo transfer (terminals); $a, g$, j, are routes of road, rail and sea transport.

Two routes are formed. The first route consists of a railway station from the starting point $A$ to the load transfer point 1 , motor road section between the transfer points 1 and 2 , sea route section between the transfer

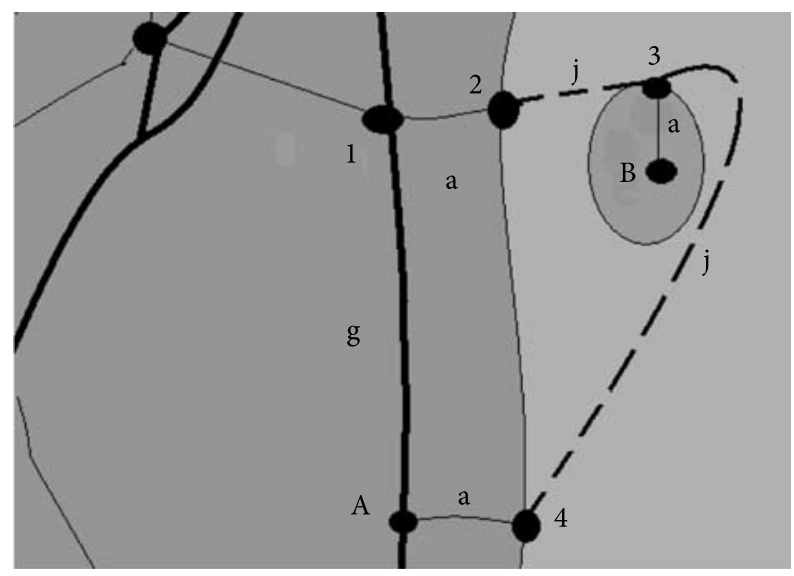

Fig. 1. A schematic view of routes for freight transportation 
points 2 and 3 and motor road section from point 3 to the finite point $B$.

The second route includes a motor road section from the starting point $A$ to the load transfer point 4, sea route section between the transfer points 4 and 3 , a motor road section from the transfer point 3 to the finite point $B$.

\subsection{The values of the quantities estimated in the case study}

The specified expected speed rates on the routes:

- in transporting goods by automobile transport: $V_{a}=70 \mathrm{~km} / \mathrm{h}$;

- in transporting goods by rail transport: $V_{g}=$ $40 \mathrm{~km} / \mathrm{h}$;

- in transporting goods by sea transport: $V_{j}=$ $25 \mathrm{~km} / \mathrm{h}$.

The specified route length of transportation, route I:

- in transporting goods by automobile transport: $l_{a 1}=150 \mathrm{~km}$;

- in transporting goods by rail transport: $l_{g 1}=$ $600 \mathrm{~km}$;

- in transporting goods by sea transport: $l_{j 1}=$ $150 \mathrm{~km}$.

The specified route length of transportation, route II:

- in transporting goods by automobile transport: $l_{a 2}=150 \mathrm{~km}$;

- in transporting goods by rail transport: $l_{g 2}=$ $0 \mathrm{~km}$;

- in transporting goods by sea transport: $l_{j 2}=$ $900 \mathrm{~km}$

The transported cargo mass is $m=2000 \mathrm{t}$.

Unplanned delay of a vehicle on the route is not estimated yet, $\tau_{a}, \tau_{g}, \tau_{j}=0$ (only technological costs are calculated).

It is considered that the insurance costs are included in tariffs, therefore, in the formula, the insurance costs are assumed to be equal to zero $(D=0)$. Otherwise, they should be estimated.

In estimating the time of transportation, it is assumed that all goods are loaded into the trucks at once, and the number of trucks does not limit the volume of goods to be carried. Otherwise, if goods had to be carried by a smaller number of trucks, the path and time of transportation would be respectively longer.

\subsection{General solution of the mathematical model}

Given a set of routes, time and costs of transportation are calculated for each of them by using the suggested methods.

When the automobile speed is $70 \mathrm{~km} / \mathrm{h}$, goods are transported in a shorter period of time $(17.14 \mathrm{~h}$ ) by route I (when carried by road, rail or sea transport). However, the expenses are smaller (110 814 EUR for carrying goods by road and sea transport) if route 2 is taken (Fig. 2).

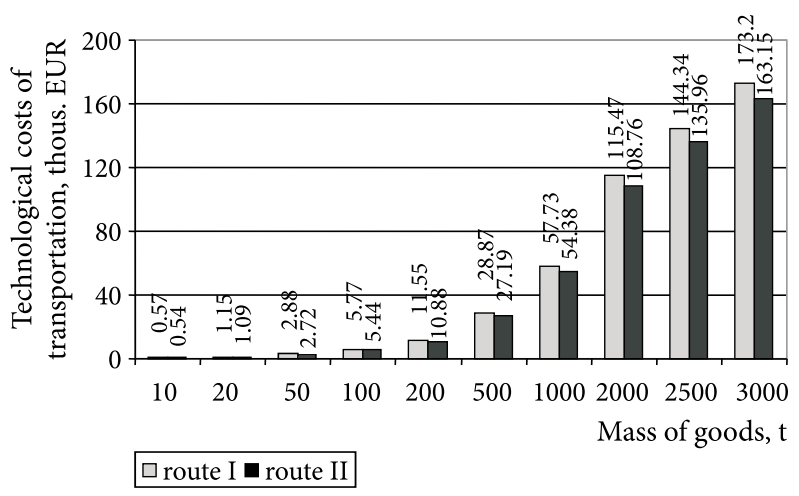

Fig. 2. The relationship between technological costs of transportation and the amount of goods carried

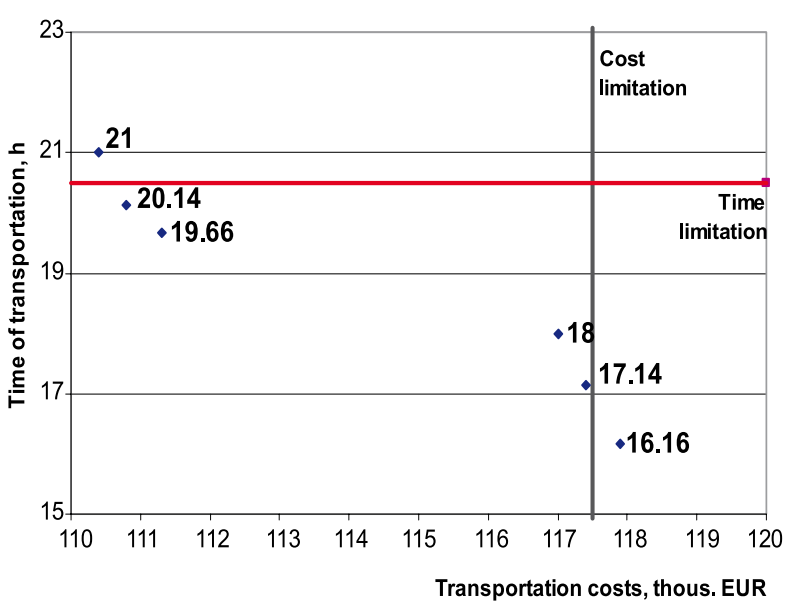

Fig. 3. A graphical view of general solution

A general solution is made up of a set of points, with the coordinates representing costs and time of transportation. In determining the efficiency functions, two limitations were made, including costs for one alternative and time for another. The points and limitations are shown in Fig. 3.

A general solution is obtained by assuming the speed to be constant for various means of transport.

In a general case, the most rational use of transport is observed on the routes, where transportation is within the limits of time and costs. However, a customer may always choose the most suitable variant.

\subsection{The relationship between transportation costs and railway tariff variation}

In various European countries the tariffs of rail transport differ considerably. So far, Lithuanian tariffs have been used in calculations. To apply the suggested methods to other (foreign) transport systems, the variability of railway tariffs (and the use of other systems if required) should be taken into account. The coefficient $b$ is used for this purpose. In the expression of the total transportation costs, a number denoting rail transport tariff is multiplied by the coefficient $b$. Then, the above expression takes the form: 


$$
\begin{aligned}
& Z=0.02107 \cdot\left(0.216+0.000952 \cdot V_{a}+\right. \\
& \left.0.0238 \cdot 10^{-3} \cdot V_{a}^{2}\right) \cdot m_{a} \cdot l_{a}+b \cdot 0.2047 \\
& l_{g}^{0.8485} \cdot m_{g} \cdot\left(0.739+0.00325 \cdot V_{g}+\right. \\
& \left.0.0814 \cdot 10^{-3} \cdot V_{g}^{2}\right)+\left(-6 \cdot 10^{-6} \cdot l_{j}^{2}+0.0677 \cdot l_{j}\right) \cdot \\
& \left(0.8483+0.00373 \cdot V_{j}+0.09338 \cdot 10^{-3} \cdot V_{j}^{2}\right) \cdot m_{j}+ \\
& \left(l_{a} / \Delta V_{a}\right) \cdot \tau_{a}+\left(l_{g} / \Delta V_{g}\right) \cdot \tau_{g}+\left(l_{j} / \Delta V_{j}\right) \cdot \\
& \tau_{j}+T_{s} \tau_{s}+\sum D ;
\end{aligned}
$$

where $b$ is a coefficient reflecting rail transport tariff variation.

This coefficient shows how much higher is the railway transport tariff in a particular region than in Lithuania as a whole. Railway transport tariffs may also depend on other factors, being an issue of negotiations.

A general solution of the considered mathematical model determining the variability coefficient $b$ of rail transport tariff is given in Fig. 4.

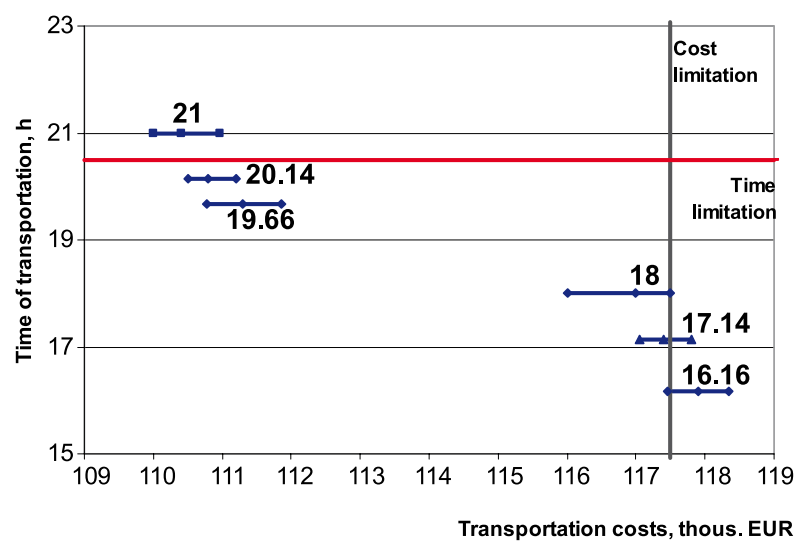

Fig. 4. A general mathematical model for determining variability coefficient $b$ of rail transport tariff

In a general solution, a set of sections is given instead of a set of points. This means that the costs of transportation on every route will differ, depending on particular rail transport tariffs. Railway tariffs vary for various reasons, i.e. depending on particular operators, time of transportation and a range of transport services provided. This implies that the total costs of carriage will vary in different ways, therefore, the length of the sections presented in the graph is also different.

\section{Conclusions}

1. The relationships established between the main factors influencing the process of freight transportation allow us to define any particular route by two generalized key criteria, i.e. transportation costs and expenses.

2. The solutions concerning the considered routes are presented in two-dimensional system of coordinates. The problem of linear programming allowing the most rational routes and transport facilities to be chosen has been solved, based on the particular conditions of transportation.
3. The correlation coefficient is $\mathrm{R}^{2}>0.9439$. This shows a relatively high confidence level.

\section{References}

Lingaitienè, O. 2006. Modelling the demand for vehicles in the logistic chain of freight transportation. Doctoral Dissertation. Technological Sciences, Transport Engineering, Vilnius Gediminas Technical University. $116 \mathrm{p}$.

TKTI. 2006. Storing and updating the data on traffic flows on the main roads of Lithuania. TKTI Report. Kaunas. 176 p.

TKTI. The revised programme of 2002-2015 for maintenance and development of the main Lithuanian roads for 20052015. TKTI Report. Kaunas, 2005. 